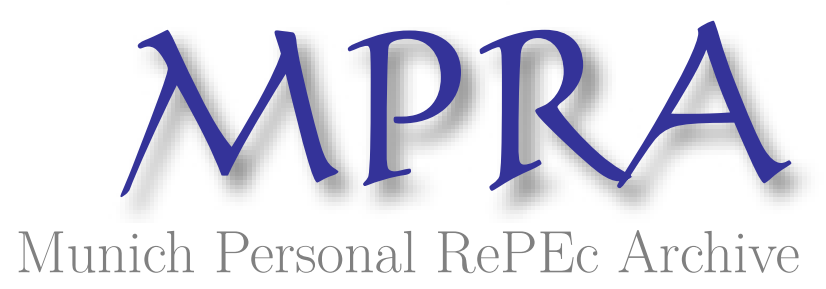

\title{
Standard errors of multipliers and forecasts from structural coefficients with block-diagonal covariance matrix
}

Bianchi, Carlo and Calzolari, Giorgio and Corsi, Paolo

Centro Scientifico IBM, Pisa, Italy

1981

Online at https://mpra.ub.uni-muenchen.de/22678/

MPRA Paper No. 22678, posted 28 May 2010 06:35 UTC 


\title{
STANDARD ERRORS OF MULTIPLIERS AND FORECASTS FROM STRUCTURAL COEFFICIENTS WITH BLOCK-DIAGONAL COVARIANCE MATRIX
}

\author{
C. Bianchi, G. Calzolari and P. Corsi \\ Centro Scientifico IBM, via S. Maria 67, 56100 Pisa, Italy
}

\begin{abstract}
For some structural econometric models, the contribution of the off-diagonal blocks of the coefficients covariance matrix to the asymptotic standard errors of multipliers and forecasts is empirically evaluated. The reasons suggesting these experiments are briefly discussed. Although the results should not be generalized, it could be useful, in the model building process, to perform the above mentioned computations, even when only the diagonal blocks of the covariance matrix of the coefficients are available.
\end{abstract}

Keywords. Econometric models; impact multipliers; forecast errors; asymptotic standard errors; structural form; reduced form; coefficients covariance matrix.

\section{INTRODUCTION} The reduced form of econometric
models, derived from structural
estimates, is of immediate concern to
the policy-maker and to the
forecaster; the impact multipliers
(which are a subset of the reduced
form coefficients) and the forecasts
are, in fact, frequently computed
both for model's validation and for
economic policy experiments.

The analysis of the stochastic properties of the restricted reduced forms has been performed by Goldberger, Nagar and Odeh (1961); in particular, for a structural linear econometric model, they have proposed formulas to obtain the covariance matrices of the reduced-form coefficients and of the forecast errors (briefly forecasts). Using simulation techniques, a, similar methodology can be applied to nonlinear models also (see, for example, Bianchi and Calzolari, 1980 , for the estimation of the standard errors of forecasts).

In order to estimate the standard errors of multipliers, one must have available a consistent estimate of all the structural coefficients and of their asymptotic covariance matrix; to obtain the standard errors of forecasts, besides the two previous estimates, the covariance matrix of the structural disturbances must be disposable.

The covariance matrix of the structural disturbances can be easily computed from estimated residuals, but the asymptotic covariance matrix of the structural coefficients is directly available only if a full-information estimation method is used. Unfortunately, it is quite difficult to apply a full-information method, especially to medium or large scale models. If a consistent 1 imited-information method is used, the covariance matrix of structural coefficients, usually supplied by any single equation method, is block-diagonal. Additional computations must be performed to obtain covariances among coefficients of different equations (off-diagonal blocks); for example, in case of 2SLS, these covariances can be computed using the formula proposed by Theil $(1971,0.500)$.

The difficulty in applying full-information methods and the burden involved in the above mentioned additional computations for limited information methods, are two of the reasons which have strongly reduced, in the model building process, the application of the formulas proposed by Goldberger, Nagar and Odeh (1961).

An evaluation of the contribution of the off-diagonal blocks (of the 
structural coefficients covariance matrix) to the asymptotic standard errors of multipliers and forecasts seems therefore worth pursuing.

The purpose of this paper is essentialiy empirical, so that no general conclusions should be derived; nevertheless, the results obtained for the iarge set of experiments performed seem to encourage the computation of asymptotic standard errors of the multipliers and of the forecasts also when the covariances between coefficients of different equations are not available.

Experiments have been performed by the authors on three econometric models; the results referred to each of them are presented and discussed in the next three sections. In the last section some conclusions on the experiments performed will be drawn.

THE RESULTS FOR THE KLEIN-I MODEL

The Klein-I model is well known in the literature on quantitative economics and it has been very often used as a "testmodel" in many experiments of applied econometrics. The endogenous variables include consumption $C$, net investment $I$, private wage bill wl, national income $Y$, profits $P$ and end-of-year capital stock $K$. For a complete description of this model and for the numerical values of the coefficients estimated by different methods, the reader is referred to Theil (1971,pp.432,517) and Chernoff and Divinsky $(1953$, P P. 250.284).

The model consists of three stochastic plus three definitional equations; 12 are the estimated coefficients, 4 for each equation. Therefore, the complete asymptotic covariance matrix of the structural estimated coefficients has dimensions $12 \times 12$ (for the numerical values of the elements of this matrix, refer again to Theil, 1971,pp.518-519 and Chernoff and Divinsky, 1953,p.288); when the covariances among coefficients of different equations are set to zero, the matrix consists of three diagonal blocks of dimensions $4 \times 4$.

Two different estimated versions of this model (2SLS, whose numerical results, originally published in Goldberger, Nagar and Odeh, 1961, have been recentiy revised in Blanchi, Calzolari and Corsi, 1979, and 3 SLS) have been analyzed.
TABLE I Klein-I Model

2SLS

$\begin{array}{cccc}\begin{array}{c}\text { Variab. Forecast } \\ \text { Name }\end{array} & \begin{array}{c}\text { Standard } \\ \text { Error }\end{array} \\ & & \begin{array}{c}\text { Complete } \\ \text { Matrix }\end{array} & \begin{array}{c}\text { Block-Diag. } \\ \text { Matrix }\end{array} \\ \text { C } & 78.2 & 2.52 & 2.64 \\ \text { I } & 9.30 & 1.69 & 1.67 \\ \text { WI } & 59.9 & 2.09 & 2.15 \\ \text { Y } & 95.7 & 4.01 & 3.97 \\ \text { P } & 27.2 & 2.37 & 2.25 \\ \text { K } & 207 . & 1.69 & 1.67\end{array}$

3SLS $\begin{array}{clc}\text { Variab. Forecast } & \text { Standard } \\ \text { Name at } 2948 & \text { Error }\end{array}$

$\begin{array}{lccc} & & \begin{array}{c}\text { Complete } \\ \text { Matrix }\end{array} & \begin{array}{c}\text { Block-Diag } \\ \text { Matrix }\end{array} \\ \text { I } & 78.5 & 2.42 & 2.54 \\ \text { WL } & 9.10 & 1.37 & 1.37 \\ \text { Y } & 60.2 & 1.79 & 1.87 \\ \text { P } & 95.8 & 3.55 & 3.54 \\ \text { K } & 26.9 & 2.25 & 2.14\end{array}$

In table 1 , for the year 1948 , forecasts and related standard errors are displayed. The standard errors have been respectively computed including and not including the off-diagonal blocks of the covariance matrix of the structural coefficients.

In tables 2 and 3 , the impact multipliers and related asymptotic standard errors for the excgenous variables $G$ (Government nonwage expenditure) and $T$ ( $T$ axes) are respectively displayed again for the two estimation methods here considered.

Very minor differences can be found in the tables between correspondent values computed with the full covariance matrix of the structural coefficients and with the block-diagonal matrix. For both estimation methods, the magnitudes of the standard errors of the forecasts are quite similar in the two cases; 
all the multipliers which are significantly different from zero in the first case are still significantly different from zero when the block-diagonal matrix is used (analogously for the multipliers which are not significantly different from zerol.

\section{TABLE 2 Klein-I Model; Impact Multipliers of Government}

\section{SLS}

$\begin{array}{cccc}\begin{array}{c}\text { Variab. Multipl. } \\ \text { Name }\end{array} & \begin{array}{c}\text { Astue } \\ \text { Vatd. Err. } \\ \text { Complete } \\ \text { Matrix }\end{array} & \begin{array}{c}\text { Block-Diag } \\ \text { Matrix }\end{array} \\ \mathrm{C} & .664 & .237 & .237 \\ \mathrm{I} & .153 & .209 & .204 \\ \mathrm{HI} & .797 & .198 & .194 \\ \mathrm{Y} & 1.82 & .421 & .389 \\ \mathrm{P} & 1.02 & .243 & .216 \\ \mathrm{~K} & .153 & .209 & .204\end{array}$

3 SLS

Variab. Multipl. Asymtotic
Name Value

$\begin{array}{cccc}\text { Complete } & \begin{array}{c}\text { Block-Diag. } \\ \text { Matrix } \\ \text { Matrix }\end{array} & .201 \\ \mathrm{H} & -.635 & .214 & .155 \\ \mathrm{Y} & .613 & .155 & .142 \\ \mathrm{P} & 1.649 & .147 & .309 \\ \mathrm{X} & .972 & .216 & .183 \\ & -.013 & .155 & .155\end{array}$

The preceding conclusions, which are valid for both 2 SLS and 3 SLS, should be slightly modified for FIML estimates. Some computations performed by the authors, not displayed here, show that, in this case. some multipliers lose significance when passing from the full matrix to the block-diagonal one. These results, however, do not contradict the previous conclusions; in fact, as pointed out in Hendry (1971,P.263), some temporal "instability in the structural coefficients" can be found when the
Klein-I model is estimated by FIML. Therefore, no conclusions should be drawn in this case, because it is difficult to separate the effects of the estimation method from those deriving from the exclusion of the off-diagonal blocks.

TABLE 3 KIein-I Model; Impact Multipliers of Taxes (I)

\section{SLS}

Variab. Multipl. Asymtotic
Name

$\begin{array}{lccc} & & \begin{array}{c}\text { Complete } \\ \text { Matrix }\end{array} & \begin{array}{c}\text { Block-Diag } \\ \text { Matrix }\end{array} \\ \text { I } & -.128 & .283 & .264 \\ \text { H1 } & -.176 & .239 & .235 \\ Y & -1.134 & .211 & .296 \\ P & -1.17 & .273 & .444 \\ K & -.176 & .239 & .249\end{array}$

3SLS

Variab. Multipl. Asymptotic Name Value Std. Err.

$\begin{array}{cccc} & & \begin{array}{c}\text { Complete } \\ \text { Matrix }\end{array} & \begin{array}{c}\text { Block-Diag. } \\ \text { Matrix }\end{array} \\ \text { I } & -.196 & .256 & .226 \\ \text { H1 } & -.014 & .177 & .177 \\ \text { Y } & -1.18 & .401 & .141 \\ \text { P } & -1.11 & .242 & .349 \\ k & .014 & .177 & .209\end{array}$

THE RESULTS FOR THE KLEIN-GOLDBERGER MODEL

In this section, the results obtained for the nonlinear revised Klein-Goldberger model (in the version described in Klein, 1969) are presented and discussed.

The model consists of sixteen stochastic and four definitional equations and includes 54 estimated coefficients. The numerical values of the coefflcients have been obtained 
TABLE 4 Klein-Goldberger Model

Variab. Forecast standard Name at 1965 Error

$\begin{array}{cccc} & & \begin{array}{c}\text { Complete } \\ \text { Matrix }\end{array} & \begin{array}{c}\text { Block-Diag. } \\ \text { Matrix }\end{array} \\ \text { Cn } & 369 . & 6.61 & 6.49 \\ \text { Im } & 303 . & 3.89 & 3.82 \\ \mathrm{X} & 530 . & 9.22 & 1.29 \\ \mathrm{H} & 311 . & 5.27 & 9.01 \\ \mathrm{p} & 1.23 & .042 & 5.11 \\ & & 1.31 & .045\end{array}$

$\frac{\text { TABLE } 5 \text { Klein-Goldberger Model; }}{\frac{\text { Impact Multipliers of }}{\text { G+E and Tat } T \text { at }}}$

$G+E$

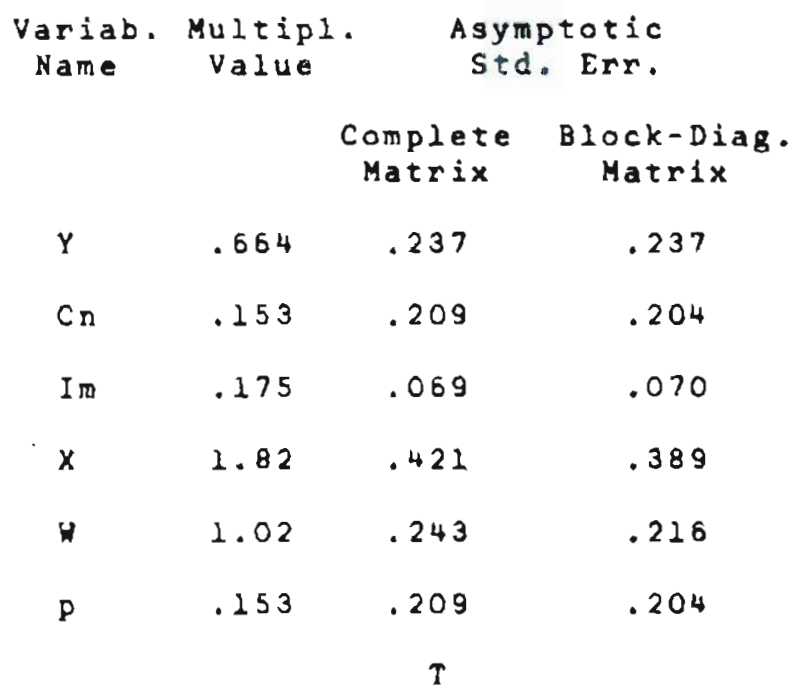
Variab. Multipl. Asymptotic
Name Value

$\begin{array}{cccc} & & \begin{array}{c}\text { Complete } \\ \text { Matrix }\end{array} & \begin{array}{c}\text { Block-Diag. } \\ \text { Matrix }\end{array} \\ \text { Cn } & -.635 & .214 & .201 \\ \text { Im } & -.013 & .155 & .155 \\ X & 1.675 & .030 & .032 \\ W & .972 & .216 & .309 \\ \text { P } & -.013 & .155 & .155\end{array}$

using 2 sLs with 4 principal components (the standard errors dtsplayed in Blanchi and Calzolarl, 1980, have been derived without the corraction for degrees of freedom and therefore differ slightly from those originally published by Kleln, $1969)$.

The complete asymptotic covariance matrix of the structural estimated coefficients has dimensions $54 \times 54$; when ignoring the covariances among coefficients of different equations, the matrix consists of 16 diagonal blocks ( 10 of dimensions $3 \times 3$ and the remaining 6 of dimengions $4 \times 4$ ).

In table 4, the results for the standard errors of the forecasts for 1965 (first year out of sample period) are displayed for the endogenous variables personal disposable income $Y$, consumption of nondurables and services $\mathrm{Cn}$, imports Im, gross national product $X$, wages and salaries $W$ and implicit deflator for gross national product $p$.

In table 5, the impact multipliers and the associated asymptotic standard errors of the exogenous variables $G+E$ (government expenditures plus exports, as they appear in the model) and $T$ (personal taxes) with respect to the same endogenous variables are reported, always for year 1965 .

Again, very minor differences between the two cases are encountered.

THE RESULTS FOR THE ISPE MODEL

The nonlinear model analyzed in this section is an annual model of the Italian economy developed by a team led by ISPE (Istituto Studi Programmazione Economica) and originally described in sartori (1978).

The model has been reestimated for the period 1955-1976 using 2SLS with principal components, according to method 4 by Kloek and Mennes (1960). It consists of 19 stochastic plus 15 definitional equations; 75 are the estimated coefficients. Compared with the $75 \times 75$ full asymptotic covariance matrix of the structural estimated coefficients, the block-diagonal matrix consists of 19 blocks, whosedimensions vary from $2 \times 2$ to, $6 \times 6$ (for a total number of 313 elements).

In table 6 , the standard errors of forecasts for 2977 (first year out of sample period) are displayed for the endogenous variables private consumption net of indirect taxes CPNCF, price deflator for exports of 
TABLE 6 ISPE ModeI

$\begin{array}{lccc}\begin{array}{c}\text { Variab. } \\ \text { Name }\end{array} & \begin{array}{c}\text { Forecast } \\ \text { at } 1977\end{array} & \begin{array}{c}\text { Standard } \\ \text { Error } \\ \text { Complete } \\ \text { Matrix }\end{array} & \begin{array}{c}\text { Block-Diag. } \\ \text { Matrix }\end{array} \\ \text { CPNCF } & 36769 . & 656 . & 685 . \\ \text { DXML } & 2.9047 & .107 & .119 \\ \text { IFIT } & 7134.8 & 381 . & 387 . \\ \text { LI } & 7706.8 & 159 . & 162 . \\ \text { MT } & 14299 . & 529 . & 556 . \\ \text { PCL } & 3.0332 & .076 & .083\end{array}$

ISPE Mode 1; Impact

Multipliers of ATI

and TRI at 1977

A I I

$\begin{array}{lccc}\begin{array}{l}\text { Variab. } \\ \text { Name } \\ \text { Value }\end{array} & \begin{array}{c}\text { Asymptotic } \\ \text { Std. Err. } \\ \text { Complete } \\ \text { Matrix }\end{array} & \begin{array}{c}\text { Block-Diag. } \\ \text { Matrix }\end{array} \\ \text { CPNCF } & -40139 . & 14394 . & 14403 . \\ \text { DXML } & 3.1861 & 1.127 & 1.223 \\ \text { IFIT } & -3785.2 & 1474 . & 1476 . \\ \text { LI } & -2270.4 & 1131 . & 1110 . \\ \text { MT } & -20442 . & 7175 . & 7105 . \\ \text { PCL } & 5.7738 & .9983 & 1.031\end{array}$

TRI

$\begin{array}{lrrr}\begin{array}{c}\text { Varlab. Mutipl. } \\ \text { Name }\end{array} & \begin{array}{c}\text { Value } \\ \text { Samptotic } \\ \text { Somplete } \\ \text { Matrix }\end{array} & \begin{array}{c}\text { Block-Diag. } \\ \text { Matrix }\end{array} \\ \text { CPNCF } & .3599 & .1302 & .1304 \\ \text { DXML } & -.00003 & .00001 & .00001 \\ \text { IFIT } & .0339 & .0133 & .0133 \\ \text { LI } & .0203 & .0102 & .0100 \\ \text { MT } & .1833 & .0650 & .0643 \\ \text { PCL } & -.00005 & .00001 & .00001\end{array}$

manufactured goods DXML, private nonresidential fixed investment in industrial and tertiary sectors IFIT, employees in the industrial sector LI, Imports of goods and services MT and price deflator for private consumption gross of indirect taxes PCL.

In table 7, the impact multipliers and the associated asymptotic standard errors of two exogenous variables (ATI, direct taxes rate and TRI, subsidies to production) with respect to the same endogenous variables are displayed, again for $197 \%$.

The results still indicate that very minor differences exist between the two cases.

\section{CONCLUSIONS}

As pointed out in the introduction, operational reasons (lack of information) and empirical motivations (needs of the policy-maker) have suggested an experimental evaluation of the effects of the covariances among structural coefficients of different equations on the asymptotic standard errors of multipliers and forecasts.

In order to give the highest heuristle content to the results, the experiments have been performed on some existing models of national economies, rather than on prototypes or ad-hoc models. Even if the choice of the models has been strongly constrained by the availability of the information necessary for the experiments, it seems that the Klein-I, the Klein-Goldberger and the ISPE models cover a wide class of econometric models, both for their different degree of nonlinearity and for their different dimensions.

For all the previous models, the experimental results lead always to the same conclusion, both including and excluding the off-diagonal blocks of the covariance matrix of the structural coefficients, so that, in the model building process, a computation of the standard errors of impact multipliers and of forecasts could be of some interest also when not all the information about the covariances of the structural coefficients are available.

\section{REFERENCES}

Bianchi,C, G.Calzolari and P.Corsi (1979): A Note on the Numerical Results by Goldberger, Nagar and Odeh. Econometrica, 47 , $505-506$. 


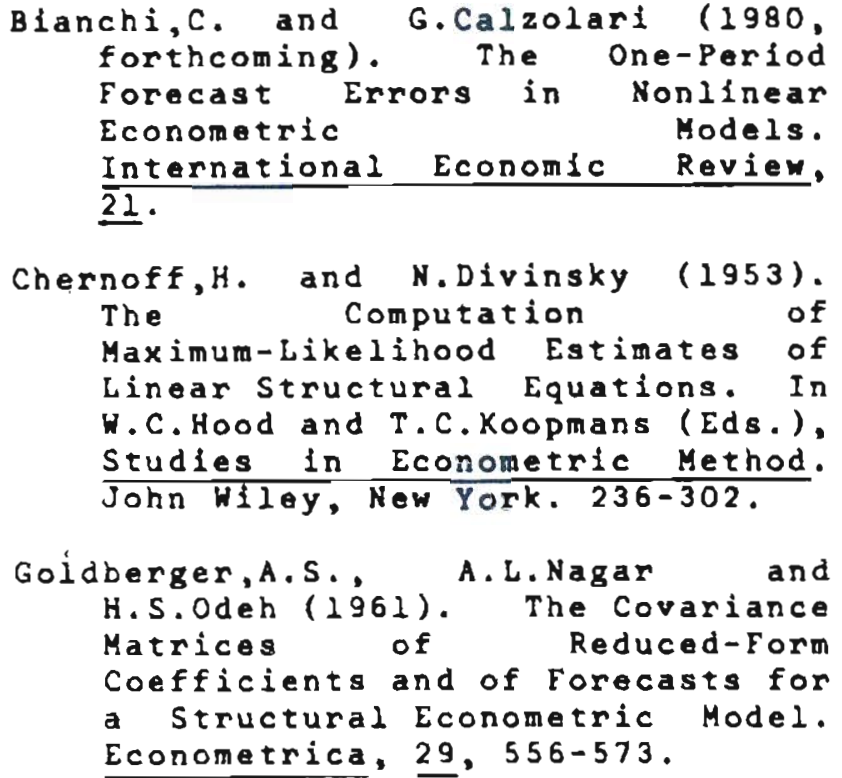

by a Vector Autoregresive Process. International Economic Review, $12,257-272$.

Klein,L.R. (1969). Estimation of Interdependent systems in Macroeconometrics. Econometrica, 37. $171-192$.

Klaek, T. and L.B.M.Mennes (1960). Simultaneous Equations Estimation Based on Principal Components of Predetermined Econometrica, 28, 45-61. Variables.

Sartori,F:(1978). Caratteristiche e Struttura del Modello. in un Modello Econometrico dell'Economia Italiana; Caratteristiche e Impiego, Ispequaderni, Roma, 1, 9-36, (in Italian).

Theil, H. (1971). Principles of Econometrics. John Wliey, New York. 